DOI: $10.1590 / 1089-6891 v 17 \mathrm{i} 126479$

PRODUÇÃO ANIMAL

\title{
GLICERINA BRUTA NAS RAÇÕES PARA LEITÕES NA FASE DE CRECHE
}

\section{CRUDE GLYCERIN IN DIETS FOR PIGLETS IN NURSING PHASE}

\author{
Laudiceia Oliveira da Rocha ${ }^{1^{*}}$ \\ Juliana Luis e Silva ${ }^{1}$ \\ Claudia Paula de Freitas Rodrigues ${ }^{1}$ \\ Alessandra Gimenez Mascarenhas ${ }^{1}$ \\ Romao da Cunha Nunes ${ }^{1}$ \\ ${ }^{1 *}$ Escola de Veterinária e Zootecnia da Universidade Federal de Goiás, Goiânia, GO, Brasil \\ *Autora para correspondência - laudiceia.zoo@gmail.com
}

\section{Resumo}

Objetivou-se avaliar a inclusão de glicerina bruta para leitões na fase de creche. No ensaio de desempenho, foram usados 80 animais machos, castrados, com peso inicial de $6,64 \pm 0,8 \mathrm{~kg}$. $\mathrm{O}$ delineamento foi de blocos ao acaso e os tratamentos consistiram em $0 \% ; 2 \% ; 4 \%$ e $6 \%$ de glicerina bruta. Houve efeito quadrático para peso final, ganho médio diário e consumo de ração, a máxima inclusão de glicerina bruta foi de $2,77 \%$ para maior consumo diário. Para o GMD, o nível de $2,76 \%$ de glicerina bruta possibilitou o melhor ganho e peso final; contudo, sem efeito na conversão alimentar. Houve diferença sobre a incidência de diarréia $(p=0,014)$, quando se incluiu $2 \%$ de glicerina bruta na dieta. Houve efeito linear decrescente na porcentagem do TGI $(p=0,006)$, intestino delgado $(p=0,038)$, rins $(p=0,089)$ e fígado $(p=0,037)$ dos leitões que não receberam glicerina bruta na ração. Observou-se efeito quadrático no peso relativo do baço e do pâncreas dos leitões, o nível de $2,73 \%$ de glicerina bruta resulta em menor peso de pâncreas e 3,04\% de glicerina aumentou o peso do baço. O nível de $2,76 \%$ de glicerina bruta promove o maior ganho de peso para leitões na fase de creche.

Palavras-chave: desempenho; digestibilidade; glicerol; suíno.

\begin{abstract}
This study evaluated the inclusion of crude glycerin for piglets in the starter phase. In the performance assay, we used 80 barrows, with initial weight of $6.64 \pm 0.8 \mathrm{~kg}$. The experimental design was of randomized blocks and the treatments consisted in $0 \%, 2 \%, 4 \%$ and $6 \%$ of crude glycerin. There was a quadratic effect on final weight, average daily gain and feed intake, the maximum inclusion of crude glycerin was of $2.77 \%$, for higher daily intake. For the ADG, the level of $2.76 \%$ of crude glycerin allowed the best gain and final weight, despite any effect on food conversion. There was a significant effect on the incidence of diarrhea $(p=0.014)$ when $2 \%$ of crude glycerin was included in the diet. There was a linear decreasing effect on the percentage of GIT $(p=0,006)$, small intestine $(p=0,038)$, kidneys $(p=0,089)$ and liver $(p=0,037)$ of piglets that did not have glycerin in the diet. We observed a quadratic effect on the relative weight of the spleen and pancreas of piglets, the level of $2.73 \%$ of crude glycerin resulted in lower pancreas weight, and $3.04 \%$ of glycerin increased spleen weight. The level of $2.76 \%$ of crude glycerin promotes the highest weight gain for piglets in the nursery phase.
\end{abstract}

Keywords: digestibility; glycerol; performance; pig.

Enviado em: 17 setembro 2013

Aceito em: 18 dezembro 2015

Cienc. anim. bras., Goiânia, v.17, n.1, p. 51-59 jan./mar. 2016 


\section{Introdução}

Com o aumento da produção do biodiesel, aumentou a disponibilidade de glicerina bruta, principal coproduto dessa cadeia, correspondendo a $10 \%$ do volume total do biodiesel ${ }^{(1,2)}$. Esse aumento de disponibilidade no mercado ocasionou a baixa no preço da glicerina, preocupações com o excedente e buscas por novas formas de aplicação.

As propriedades físico-químicas da glicerina a tornam um composto versátil, com grande variedade de aplicações na indústria farmacêutica, bélica e alimentícia ${ }^{(3)}$. A molécula do glicerol está relacionada a inúmeros processos metabólicos, exercendo importante função fisiológica como fonte de energia, agente crioprotetor e osmorregulador para diversos microrganismos e animais ${ }^{(4)}$. Estas constatações estimularam a realização de pesquisas quanto ao uso de glicerina bruta na alimentação animal, com destaque para a espécie suína ${ }^{(5,6)}$.

Com a finalidade de reduzir o custo das dietas de suínos, sobretudo o custo energético, a glicerina bruta passou a ser incluída nas rações de leitões na fase de creche $^{(7)}$. Por tratar-se de um produto de sabor adocicado, com boa palatabilidade e alta digestibilidade ${ }^{(5,8-9)}$, podendo substituir em parte cereais ${ }^{(5)}$, como também a lactose e o soro de leite em pó ${ }^{(2,10-11)}$, ingredientes tradicionalmente incluídos nas dietas de pós-desmame como fontes energéticas de alta digestibilidade, é um ingrediente alternativo que poderá facilitar a transição da dieta líquida (leite da porca) para a dieta sólida.

O período pós-desmama é marcado pelo consumo reduzido de alimento, mobilização de reserva energética do leitão e alterações na mucosa intestinal, que ocorrem em função da mudança da dieta, reduzindo a capacidade de digerir e absorver os nutrientes ${ }^{(12)}$. O uso de glicerina nas dietas de leitões na fase de creche poderá reduzir as complicações associadas com a fase pós-desmame, uma vez que é fonte energética de rápida absorção intestinal, por ser constituinte do processo metabólico da glicólise, gliconeogênese e da lipogênese. Dessa forma, a glicerina poderá desempenhar relevante papel nutricional e fisiológico com interferência positiva sobre o desempenho de suínos na fase de creche. Nesse sentido, objetivou-se avaliar a inclusão de glicerina bruta nas dietas de leitões na fase de creche.

\section{Material e Métodos}

O projeto experimental foi submetido à Comissão de Ética no Uso de Animais (CEUA), da Universidade Federal de Goiás, e protocolado sob o número 073/2012. O ensaio foi desenvolvido no Setor de Suinocultura da Escola de Veterinária e Zootecnia da Universidade Federal de Goiás e consistiu na avaliação do desempenho dos animais machos castrados, híbridos comerciais, de 23 a 70 dias de idade.

Os tratamentos testados foram de rações fareladas à base de milho e farelo de soja contendo quatro níveis de glicerina bruta $(0 \%, 2 \%, 4 \%$ e $6 \%)$ (Tabela 1$)$. As rações eram isonutritivas, formuladas para atender às exigências nutricionais dos animais segundo recomendações de Rostagno et al. ${ }^{(13)}$.

$\mathrm{O}$ delineamento experimental foi de blocos ao acaso, baseado no peso dos animais, com quatro tratamentos e cinco repetições, perfazendo o total de 20 unidades experimentais. Foram utilizados 80 animais híbridos comerciais (Agroceres vs Danbred), com pesos de desmama de 6,64 0,8 $\mathrm{kg}$ e com média de 23 dias de vida. Cada unidade experimental foi composta por quatro animais, alojados em gaiolas suspensas com $2 \mathrm{~m}^{2}$, um comedouro de PVC com duas bocas e um bebedouro automático, tipo chupeta. $\mathrm{O}$ consumo de ração e água foi à vontade. $\mathrm{O}$ período experimental final foi até os animais atingirem média de $30,79 \pm 0,84 \mathrm{~kg}$.

Foi mensurado o escore fecal dos animais, com a verificação diária e sempre às $17 \mathrm{~h}$. A consistência das fezes foi classificada em 0 - fezes com consistência normal; 1 - fezes moles; 2 - fezes pastosas; 3 - fezes líquidas ou aquosas. Os escores de fezes de 0 e 1 foram considerados não diarréicos e 2 e 3 com diarreia ${ }^{(14)}$. 
Foi abatido um animal por tratamento e por repetição, totalizando 20 animais. Os animais foram insensibilizados, por meio de choque elétrico de alta voltagem e baixa amperagem nas fossas temporais. Em seguida, foram dessangrados e imediatamente foi feita a abertura abdominal desde o esterno até o púbis.

Todo o trato gastrointestinal foi retirado e pesado (estômago cheio e vazio, intestino delgado e intestino grosso), também foram pesados o fígado, os rins, o pâncreas e o baço. As pesagens foram usadas para mensurar o peso absoluto e a relação órgão/corpo. No conteúdo do jejuno, duodeno, íleo, ceco, cólon e reto foi efetuada a leitura do pH por meio da inserção de eletrodo unipolar (pH100/pHTek $\left.{ }^{\circledR}\right)^{(15)}$. Foram colhidas duas amostras de aproximadamente $1,0 \mathrm{~cm}$ de comprimento por segmento intestinal (duodeno, jejuno e íleo) de cada animal. As amostras foram lavadas em solução de formaldeído e fixadas por imersão em formol tamponado (10\%). Após 24 horas na solução de fixação, as amostras foram lavadas em álcool $70 \%$ e posteriormente foram desidratadas conforme Luna (16). Após a desidratação, procedeu-se o recorte e imersão das amostras em parafina para obtenção dos cortes longitudinais, para confecção das lâminas histológicas. As lâminas continham duas seções cortadas a $4 \mu \mathrm{m}$, coradas com hematoxilina e eosina.

Tabela 1: Composição centesimal e nutricional das dietas experimentais para leitões na fase de creche

\begin{tabular}{|c|c|c|c|c|}
\hline Ingredientes & T1 & T2 & T3 & T4 \\
\hline Milho grão & 69,69 & 67,30 & 64,94 & 62,56 \\
\hline Farelo de soja $45 \%$ & 25,79 & 26,26 & 26,73 & 27,20 \\
\hline Glicerina bruta & 0,00 & 2,00 & 4,00 & 6,00 \\
\hline Óleo de Soja & 1,01 & 0,93 & 0,85 & 0,77 \\
\hline Fosfato bicálcico & 1,40 & 1,40 & 1,41 & 1,41 \\
\hline Calcário & 0,74 & 0,73 & 0,73 & 0,72 \\
\hline Sal comum & 0,41 & 0,41 & 0,41 & 0,41 \\
\hline Suplemento mineral e vitamínico ${ }^{*}$ & 0,50 & 0,50 & 0,50 & 0,50 \\
\hline L- Lisina HCL & 0,34 & 0,33 & 0,32 & 0,32 \\
\hline L- Treonina & 0,09 & 0,09 & 0,09 & 0,09 \\
\hline DL-Metionina & 0,03 & 0,03 & 0,03 & 0,03 \\
\hline L- Triptofano & 0,01 & 0,03 & 0,00 & 0,00 \\
\hline Total & 100,0 & 100,0 & 100,0 & 100,0 \\
\hline Variáveis & \multicolumn{4}{|c|}{ Niveis } \\
\hline Energia metabolizável (kcal $/ \mathrm{kg})$ & \multicolumn{4}{|c|}{3.230} \\
\hline Proteina Bruta (\%) & \multicolumn{4}{|c|}{18,13} \\
\hline Lisina Digestivel (\%) & \multicolumn{4}{|c|}{1,04} \\
\hline Metionina Digestivel (\%) & \multicolumn{4}{|c|}{0,29} \\
\hline Treonina Digestível (\%) & \multicolumn{4}{|c|}{0,65} \\
\hline Triptofano Digestivel (\%) & \multicolumn{4}{|c|}{0,19} \\
\hline Cálcio (\%) & \multicolumn{4}{|c|}{0,73} \\
\hline Sódio (\%) & \multicolumn{4}{|c|}{0,20} \\
\hline Fósforo Disponivel (\%) & \multicolumn{4}{|c|}{0,36} \\
\hline
\end{tabular}

"Suplemento mineral e vitamínico: $5 \mathrm{mg}$ de cobre; $80 \mathrm{mg}$ de zinco; $80 \mathrm{mg}$ de ferro; $20 \mathrm{mg}$ de manganês; $0,25 \mathrm{mg}$ de selênio e $0,14 \mathrm{mg}$ de I; $6.000 \mathrm{UI}$ vit. A; $1.320 \mathrm{UI}$ vit D3; $12 \mathrm{mg}$ vit. $\mathrm{E} ; 1,47$ $\mathrm{mg}$ vit. $\mathrm{K} 3 ; 0,9 \mathrm{mg}$ vit. $\mathrm{B} 1 ; 3 \mathrm{mg}$ vit. $\mathrm{B} 2 ; 1,8 \mathrm{mg}$ vit. $\mathrm{B} 6 ; 12 \mathrm{mcg}$ vit. B12;0,3 $\mathrm{mg}$ ác. fólico; 9,3 $\mathrm{mg}$ ác. pantotênico; $18 \mathrm{mg}$ niacina; $0,09 \mathrm{mg}$ biotina; $240 \mathrm{mg}$ de colina. 
As medições foram feitas mediante sistema de análise de imagem com ampliação de 10x (Microscópio Leica, Câmera Leica e software ImageJ). Foram medidas em cada seção dez alturas das vilosidades (VH), dez larguras das vilosidades (VW) e dez profundidades das criptas (CD). A média das medidas $\mathrm{VH}, \mathrm{VW}$ e CD foram tratadas como a unidade experimental. A relação vilosidade/cripta foi calculada dividindo-se a altura das vilosidades pela profundidade das criptas. A área de superfície de absorção foi determinada mediante a fórmula $\mathrm{S}(1)+(2)=\pi(\mathrm{r} 2 / \mathrm{R})+\pi(\mathrm{R}+\mathrm{r}) \times \sqrt{ } \mathrm{h} 2+(\mathrm{R}-\mathrm{r}) 2$, em que: R: medida da base/2; r: medida do ápice/2; h: altura da vilosidade ${ }^{(15,17)}$. A análise histomorfométrica foi realizada pela mesma pessoa.

Os dados de consumo de ração total (CRT) e diário (CRD), ganho médio total (GMT) e ganho médio diário (GMD), conversão alimentar (CA), peso das vísceras, $\mathrm{pH}$ intestinal e medidas histomorfométricas foram submetidos a análise de variância e análise de regressão, adotando-se $\alpha=0,10$. A ocorrência de diarréia foi submetida à análise de Qui-quadrado, adotando-se $\alpha=0,10$. Foi usado o programa computacional SAS ${ }^{(18)}$.

\section{Resultados e Discussão}

Não houve diferença na conversão alimentar dos leitões na fase de creche alimentados com glicerina bruta (Tabela 2). Contudo, observou-se efeito quadrático para peso final, ganho médio diário e consumo diário de ração. O nível máximo de inclusão de $2,76 \%$ de glicerina bruta resultou no maior peso final e melhor ganho médio diário. Para o maior consumo médio, o valor de inclusão de glicerina é de $2,77 \%$.

Esses resultados assemelham-se com os obtidos por Kijora \& Kupsch ${ }^{(19)}$, que também observaram aumento no GMD de leitões ao receberem dietas suplementadas com glicerina. Em outro estudo, Kijora et al. ${ }^{(20)}$ testaram o uso de glicerina bruta para leitões de $27 \mathrm{~kg}$ e descreveram que a adição de $10 \%$ de glicerina bruta contribuiu para o maior consumo de ração e ganho de peso diário.

O estímulo do consumo de rações na fase de creche e melhoria na eficiência da alimentação tem sido associado ao sabor adocicado das dietas suplementadas com glicerina bruta ${ }^{(21)}$. A melhoria do CRD pode esta associada à palatabilidade das rações, uma vez que ingredientes com melhores propriedades organolépticas têm sido apontados como estimuladores de consumo. Dietas atrativas, com ingredientes palatáveis e com alta digestibilidade, têm propiciado aumento de ingestão de leitões, sobretudo no pós-desmame.

Tabela 2: Peso Inicial, peso final, ganho médio diário (GMD); consumo diário de ração (CDR) e conversão alimentar (CA) de leitões alimentados com dietas com níveis de glicerina bruta na fase creche ( 23 a 70 dias)

\begin{tabular}{lllllll}
\hline Variáveis* $^{*}$ & $\mathbf{0 \%}$ & $\mathbf{2 \%}$ & $\mathbf{4 \%}$ & $\mathbf{6 \%}$ & $\mathbf{C V}^{* *}$ & $\mathbf{P}^{* * *}$ \\
\hline Peso Inicial $(\mathrm{kg})$ & 6,64 & 6,64 & 6,65 & 6,65 & 0,3 & $<0,0001$ \\
Peso final $(\mathrm{kg})^{1}$ & 29,75 & 33,15 & 30,67 & 29,70 & 5,7 & 0,085 \\
$\mathrm{GMD}(\mathrm{kg} / \mathrm{d})^{2}$ & 0,481 & 0,551 & 0,501 & 0,478 & 7,3 & 0,055 \\
$\mathrm{CDR}(\mathrm{kg} / \mathrm{d})^{3}$ & 0,821 & 0,925 & 0,862 & 0,816 & 5,3 & 0,003 \\
$\mathrm{CA}$ & 1,71 & 1,68 & 1,73 & 1,71 & 5,0 & 0,914 \\
\hline
\end{tabular}

*Valores médios de $\mathrm{n}=20$; ${ }^{*} \mathrm{CV}$ : coeficiente de variação; *** $\mathrm{P}$ : valor da análise de variância; ${ }^{1,2,3}$ Efeito quadrático: ${ }^{1} \mathrm{PF}=-0,2706$ glicerina $^{2}+1,492$ glicerina $+30,113$; $\left(R^{2}=0,655\right) ;{ }^{2} \mathrm{GMD}=-0,0062$ glicerina ${ }^{2}+0,0342$ glicerina $+0,5333 ;\left(\mathrm{R}^{2}=0,653\right) ;{ }^{3} \mathrm{CRD}=-$ 0,0104 glicerina $a^{2}+0,0576$ glicerina $+0,8326 ;\left(R^{2}=0,7315\right)$. 
As pesquisas divergem quanto aos níveis de inclusão de glicerina de acordo com o tipo (bruta, semipurificada e/ou neutralizada). São estabelecidos níveis de até $10 \%$ para glicerina bruta ${ }^{(5)}, 12 \%$ de glicerina semipurificada ${ }^{(22)}$ e $14 \%$ de glicerina semipurificada neutralizada ${ }^{(23)}$, sem prejuízo ao desempenho dos leitões de 15 a $30 \mathrm{~kg}$. Portanto, o processo de separação do biodiesel, a purificação da glicerina bruta, bem como o tipo de ração (granulada ou peletizada) serão determinantes para se estabelecerem os níveis de inclusão. Neste estudo, não se observou efeito negativo quando se incluíram níveis de até $6 \%$ de glicerina bruta nas dietas de leitões de 6,5 a $30 \mathrm{~kg}$. No entanto, torna-se importante observar o custo de inclusão da glicerina bruta nas dietas de leitões e se isso contribuiu para minimizar o custo da dieta.

Houve efeito significativo para a incidência de diarréia na fase de creche $(\mathrm{p}=0,014)$ (Tabela 3$)$, sendo que o nível de $2 \%$ resultou na menor incidência de diarreia. Os diferentes níveis de glicerina bruta nas dietas não podem ser associados à prevenção, tampouco à incidência de diarréia após desmama ou até mesmo na fase de creche. A qualidade nutricional da dieta, especialmente relacionada aos ingredientes digestíveis como plasma sanguíneo, leite em pó desnatado, lactose e até mesmo glicerina bruta pode ter sido importante no controle da microbiota patogênica e na ocorrência de diarréias.

A melhor consistência fecal se deve à boa digestibilidade e ao aproveitamento eficiente do alimento pelos animais. Durante toda a fase de creche $(6,5 \mathrm{a} 30 \mathrm{~kg})$, a menor incidência de diarréias foi observada no grupo de animais que receberam dietas com $2 \%$ de glicerina bruta. Essa menor incidência pode ser um dos fatores que contribuíram com o melhor ganho médio de peso e melhor consumo diário de ração, conforme dispostos nas tabelas de desempenho.

Tabela 3: Ocorrência de diarréias em leitões na fase de creche alimentados com glicerina bruta*

\begin{tabular}{lccccc}
\hline Tratamentos & SEM $^{* *}$ & $\%$ & COM $^{* * *}$ & \% & P-Valor \\
\hline $0 \%$ & 855 & 88,24 & 114 & 11,76 & \\
$2 \%$ & 868 & 89,58 & 101 & 10,42 & P=0,014 \\
$4 \%$ & 844 & 87,10 & 125 & 12,90 & \\
$6 \%$ & 822 & 84,83 & 147 & 15,17 & \\
\hline
\end{tabular}

*Análise de Qui-quadrado; **Sem diarréia (0 - fezes normais; 1 - fezes moles); ${ }^{* * *}$ Com diarréia (2 - fezes pastosas; 3 - fezes aquosas ou liquidas).

Diversos fatores podem ter sido preponderantes na incidência de diarréias, sobretudo nos primeiros 14 dias pós-desmame. Fatores estressantes, como a separação da porca, o transporte, o novo ambiente e as novas organizações hierárquicas, podem provocar alterações histomorfológicas, deixando o leitão mais exposto às perturbações intestinais. Assim, o fornecimento de dietas de qualidade, com ingredientes de alta digestibilidade, permite promover a melhora na saúde intestinal, redução do $\mathrm{pH}$ e o aumento da população de lactobacilos intestinais, com redução da ocorrência de diarréia.

As variáveis peso do trato digestivo e peso relativo do fígado, rins e intestino delgado apresentaram efeito linear decrescente, os animais que recebiam dietas com $0 \%$ de glicerina bruta apresentaram maior porcentagem em relação aos demais tratamentos (Tabela 4). Os pesos dos órgãos podem variar de acordo com o consumo de energia e/ou proteína ${ }^{(24)}$. GOMES et al. ${ }^{(25)}$ relataram que maiores pesos dos órgãos do sistema digestivo e órgãos não digestivos, bem como o maior comprimento do intestino delgado em leitões, podem afetar negativamente a eficiência alimentar, uma vez que o animal utiliza, para a sua manutenção, a energia que seria destinada à produção. Não houve efeito negativo sobre a eficiência alimentar, como se pode observar na Tabela 2, de desempenho de leitões na fase de creche. Observou-se efeito quadrático no peso relativo do baço e do pâncreas dos leitões, o nível de $2,73 \%$ de glicerina bruta resultou em menor peso de pâncreas e 3,04\% de glicerina aumentou o peso do baço. A suplementação elevada de glicerina pode suplantar a capacidade que o sistema enzimático dispõe para sua metabolização. Níveis de $20 \%$ de glicerina na dieta de ratos aumentaram o peso do fígado ${ }^{(26)}$. Oliveira et al. ${ }^{(11)}$ observaram efeito linear na urina de leitões no pós-desmame, à medida que aumentou os níveis de 
glicerina bruta nas dietas, indicando uma possível saturação na via metabólica de utilização do glicerol (21, 27). No entanto, não houve aumento do peso relativo do fígado em relação aos tratamentos testados, visto que o fígado é o local de degradação de aminoácidos, metabolismo de nitrogênio e glicerol. Porém a maior porcentagem do fígado foi do grupo controle.

Tabela 4: Carcaça eviscerada, peso relativo de órgãos e $\mathrm{pH}$ em diferentes segmentos do trato gastrointestinal de leitões na fase de creche alimentados com glicerina bruta

\begin{tabular}{|c|c|c|c|c|c|c|c|}
\hline Variáveis* & & $0 \%$ & $2 \%$ & $4 \%$ & $6 \%$ & $\mathrm{CV}^{2}$ & $\mathbf{P}$ \\
\hline Carcaça eviscerada (g) & & 26,34 & 27,04 & 25,86 & 26,35 & 4,2 & 0,855 \\
\hline Trato digestivo $(\% \mathrm{PV})^{1}$ & & 15,84 & 14,92 & 14,20 & 13,66 & 6,0 & 0,006 \\
\hline Fígado $(\% \mathrm{PCV})^{2}$ & & 3,85 & 3,52 & 3,33 & 3,25 & 13,2 & 0,037 \\
\hline Rins $(\% \mathrm{PCV})^{3}$ & & 0,81 & 0,78 & 0,70 & 0,68 & 17,6 & 0,089 \\
\hline Baço $(\% \mathrm{PCV})^{4}$ & & 0,20 & 0,27 & 0,23 & 0,22 & 19,4 & 0,090 \\
\hline Pâncreas (\%PCV) 5 & & 0,24 & 0,20 & 0,21 & 0,26 & 20,7 & 0,031 \\
\hline Estômago vazio (\%PCV) & & 0,91 & 0,90 & 0,92 & 0,88 & 11,0 & 0,876 \\
\hline Intestino delgado $(\% \mathrm{PCV})^{6}$ & & 8,94 & 8,11 & 7,55 & 7,27 & 13,1 & 0,038 \\
\hline Intestino grosso $(\% \mathrm{PCV})$ & & 6,72 & 6,93 & 5,72 & 5,60 & 19,9 & 0,207 \\
\hline Estômago vazio (\%TGI) & & 4,86 & 5,13 & 5,59 & 5,60 & 12,4 & 0,143 \\
\hline Intestino delgado (\%TGI) & & 47,26 & 46,18 & 45,82 & 45,91 & 7,2 & 0,747 \\
\hline Intestino grosso ( $\% \mathrm{TGI})$ & & 35,60 & 39,43 & 35,14 & 35,61 & 19,3 & 0,831 \\
\hline $\mathrm{pH}^{*}$ & $0 \%$ & $2 \%$ & & $4 \%$ & $6 \%$ & $\mathrm{CV}^{*}$ & $\mathrm{P}^{* * *}$ \\
\hline Estômago & 2,8 & 3,1 & & 3,08 & 3,92 & 30,8 & 0,231 \\
\hline Duodeno & 5,8 & 4,4 & & 5,6 & 5,9 & 25,0 & 0,288 \\
\hline Jejuno & 6,4 & 6,1 & & 6,3 & 6,3 & 6,8 & 0,758 \\
\hline Íleo & 4,5 & 4,8 & & 6,2 & 6,4 & 34,9 & 0,350 \\
\hline $\mathrm{Ceco}$ & 5,4 & 5,4 & & 5,5 & 5,6 & 6,3 & 0,437 \\
\hline Colón & 5,9 & 5,7 & & 5,8 & 6,0 & 4,6 & 0,102 \\
\hline Reto & 6,6 & 6,8 & & 6,4 & 6,7 & 8,1 & 0,992 \\
\hline
\end{tabular}

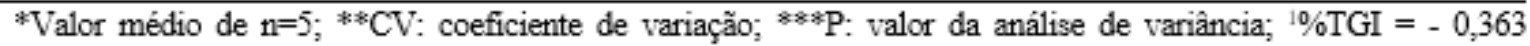

Glicerina + 15,744 $\left(R^{2}=0,9865\right) ;{ }^{2}$ Figado $=0,0161-0,0995$ Glicerina $+3,786\left(R^{2}=0,9267\right) ;{ }^{3}$ Rins $=-0,0235$

Glicerina $+0,813\left(R^{2}=0,946\right) ;{ }^{4}$ Baço $=-0,005$ Glicerina $^{2}+0,031$ Glicerina $+0,207\left(R^{2}=0,6231\right) ;{ }^{5}$ Pancreas $=$ 0,0056 Glicerina $^{2}-0,0303$ Glicerina $+0,2395\left(R^{2}=0.9978\right) ; \% \% \mathrm{D}=-0,2785$ Glicerina $+8,803\left(R^{2}=0,9535\right)$

Não houve diferenças no $\mathrm{pH}$ dos segmentos medidos $(\mathrm{P}>0,10)$. O consumo de alimentos e os tipos de ingredientes fornecidos aos leitões têm por finalidade permitir o desenvolvimento, amadurecimento do TGI e do pH ideal. Não foi observada irritação da mucosa intestinal, referente à infecção, injúria ou toxidez, que alterasse de modo anormal o peso dos órgãos dos animais.

Houve efeito quadrático na altura de vilosidade e área de superfície de contato no duodeno (Tabela 5). O nível de glicerina bruta de $4,88 \%$ resultou no achatamento da base da vilosidade e, consequentemente, no aumento da área de contato, a partir do nível de 3,49\% de glicerina.

Não houve diferenças nas variáveis analisadas no segmento de jejuno; entretanto, no íleo, houve efeito linear crescente para altura da vilosidade e superfície de contato. O fornecimento da ração com alto valor nutricional e digestivo promovem menores alterações digestivas ${ }^{(28)}$. Alterações histomorfométricas estão associadas à falta de suprimento contínuo de alimento, o que não ocorreu com os leitões após a desmama. 
Tabela 5: Histomorfometria intestinal de leitões na fase de creche alimentados com glicerina bruta

\begin{tabular}{lcccccc}
\hline Variáveis* $(\boldsymbol{\mu m})$ & $\mathbf{0 \%}$ & $\mathbf{2 \%}$ & $\mathbf{4 \%}$ & $\mathbf{6 \%}$ & $\mathbf{C V}^{* * *}$ & $\mathbf{P}^{* * \star}$ \\
\hline Duodeno & & & & & & \\
Altura de Vilosidade & 1133,1 & 1166,2 & 1220,6 & 1040,7 & 16,6 & 0,119 \\
Base da vilosidade & 463,9 & 483,2 & 551,6 & 520,3 & 12,7 & 0,029 \\
Superficie de contato & 1231050 & 1300277 & 1505275 & 1282989 & 19,3 & 0,018 \\
Profundidade de cripta & 660,5 & 749,5 & 728,5 & 668,5 & 18,3 & 0,456 \\
Vilosidade:cripta & 1,74 & 1,58 & 1,69 & 1,56 & 17,1 & 0,675 \\
Jejuno & & & & & & \\
Altura de Vilosidade & 1244,1 & 954,4 & 1177,6 & 1063,7 & 17,2 & 0,101 \\
Base da Vilosidade & 528,9 & 536,7 & 500,9 & 589,7 & 13,0 & 0,307 \\
Superficie de contato & 1487450 & 1156664 & 1313200 & 1674778 & 36,9 & 0,810 \\
Profundidade de cripta & 749,2 & 764,6 & 739,5 & 738,7 & 17,2 & 0,911 \\
Vilosidade:cripta & 1,68 & 1,26 & 1,62 & 1,51 & 26,8 & 0,519 \\
Ileo & & & & & & \\
Altura de Vilosidade & 471,8 & 506,3 & 479,4 & 562,9 & 16,6 & 0,082 \\
Base da Vilosidade & 909,5 & 1047,9 & 1017,8 & 1008,3 & 17,4 & 0,253 \\
Superficie de contato & 1023748 & 1219587 & 1126048 & 1271601 & 23,6 & 0,064 \\
Profundidade de cripta & 477,8 & 591,1 & 551,9 & 618,2 & 21,4 & 0,304 \\
Vilosidade:cripta & 1,04 & 0,867 & 0,857 & 0,919 & 21,6 & 0,574 \\
\hline
\end{tabular}

*Valores de $n=5$;* CV: coeficiente de variação; **P: valor da análise de variância; Base da vilosidade $=$ 3,1556 Glicerina $^{2}+30,819 x+456,43\left(R^{2}=0,7582\right)$; Area de contato $=-18220$ Glicerina $^{2}+127358$ Glicerina $+10 \mathrm{e}^{5}\left(\mathrm{R}^{2}=0,6365\right)$; Altura de vilosidade $=12,32$ Glicerina $+468,14\left(\mathrm{R}^{2}=0,5939\right)$; Área de contato $=32501$ Glicerina $+10 \mathrm{e}^{05}\left(\mathrm{R}^{2}=0,5914\right)$

Oliveira et al. ${ }^{(11)}$ não observaram diferenças nas medidas de morfometrias no intestino delgado de leitões que receberam dietas com níveis de $9 \%$ e $18 \%$ de glicerina bruta. Contudo, observaram aumento do número de células secretoras de IgA no jejuno ao adicionarem 9\% de glicerina bruta; diferenças na expressão de RNAm com o aumento de $9 \%$ e $18 \%$ de glicerina bruta no jejuno e íleo e redução das células caliciformes no íleo. Estas alterações estão relacionadas à produção do muco protetor que recobre a superfície do epitélio intestinal. Portanto, mudanças na composição e espessura do muco resultam em alterações inflamatórias e perturbação na absorção dos nutrientes. Os autores atribuem as alterações verificadas à diminuição de ácido láctico na digesta dos leitões que receberam glicerina bruta nas dietas. A estrutura celular e expressão citoquímica do intestino podem ser afetadas quando níveis altos de glicerina bruta são incluídos nas dietas de leitões, o que leva à necessidade de maiores estudos sobre esses parâmetros.

As variáveis, altura de vilosidade e profundidade de cripta são indicadores importantes da saúde do aparelho digestivo dos leitões e estão diretamente relacionadas com a capacidade de absorção da membrana mucosa. A altura das vilosidades reflete o equilíbrio entre a atividade mitótica das células das criptas e a descamação produzida por agressores externos ${ }^{(29)}$. As medidas de histomorfometria nos segmentos do intestino delgado encontram-se em escala comparável com os dados obtidos por Cera et al. ${ }^{(29)}$ e Manzanilla et al. ${ }^{(30)}$.

\section{Conclusão}

O nível de 2,76\% de glicerina bruta promove o maior ganho de peso para leitões na fase de creche. 


\section{Agradecimentos}

Agradeço à CAPES; à FUNAPE pelo apoio financeiro, e às empresas CARAMURU, MCASSAB e HAWK nutrientes pela doação de ingredientes para as rações experimentais.

\section{Referências}

1. Ma F, Hanna MA. Biodiesel production: A review. Bioresource Technology. 1999; 70:1-15.

2. Shields MC Van Heugten E, Lin X, Odle J, Stark C S. Evaluation of the nutritional value of glycerol for nursery pigs. Journal of Animal Science. 2011; 89: 2145-2153.

3. Gaudré D. Valeurs nutritionnelles du glycérol pour le porc: État des lieux des connaissances disponibles. Techni Porc. 2009; 32 (2): 9 -14.

4. Arruda PV, Rodrigues RCLB, Felipe MGA. Glicerol: um subproduto com grande capacidade industrial e metabólica. Revista Analytica. 2007; 26: 56-62.

5. Lammers PJ, Kerr BJ, Weber TE, Bregendahl K, Lonergan SM, Prusa KJ, Ahn DU, Stoffregen WC, Dozier WA, Honeyman M S. Growth performance, carcass characteristics, meat quality, and tissue histology of growing pigs fed crude glycerin supplemented diets. Journal of Animal Science. 2008b; 86:2962-2970.

6. Thompson JC, He BB. Characterization of crude glycerol from biodiesel production from multiple feed stocks. Applied Engineering in Agriculture. 2006; 22: 261-265.

7. Zijlstra RT, Menjivar K, Lawrence E, Beltranena E. The effect of feeding crude glycerol on growth performance and nutrient digestibility in weaned pigs. Journal of Animal Science. 2009; 89: 85-89.

8. Lammers PJ, Kerr B J, Honeyrnan MS, Bregendahl SM, Lonergan KJ, Prusa DU, Ahn WC, Stoffregen WA, Dozier IMT, Honeyman MS. Nitrogen-corrected apparent metabolizable energy value of crude glycerol for laying hens. Poultry Science. 2008a; 87:104-107.

9. Wapnir RA, Sai MC, Fisher SE. Enhancement of intestinal water absorption and sodium transport by glycerol in rats. Journal of Applied Physiology. 1996; 81: 2523-2527.

10. Groesbeck CN, Mckinney LJ, Derouchey JM, Tokach MD, Goodband RD, Dritz S S, Nelssen J L, Duttlinger AW, Fahrenholz AC, Behnke KC. Effect of crude glycerol on pellet mill production and nursery pig growth performance. Journal of Animal Science. 2008; 86: 2228-2236.

11. Oliveira L, Madrid J, Ramis G, Martínez S, Orengo J, Villodre C, Valera L, López MJ, Pallarés FJ, Quereda JJ, Mendonça L., Hernández F. Adding crude glycerin to nursery pig diet: Effect on nutrient digestibility, metabolic status, intestinal morphology and intestinal cytokine expression. Livestock Science. 2014;167: $227-$ 235.

12. Lallés JP, Bosi P, Smidt H, Stokes CR. Nutritional management of gut health in pigs around weaning. Proceedings of the Nutrition Society. 2007; 66: 260-268.

13. Rostagno HS, Albino LFT, Donzele JL, Gomes PC, Oliveira RF, Lopes DC, Ferreira AS, Barreto SLT. Tabelas brasileiras para aves e suínos: Composição de alimentos e exigências nutricionais. Viçosa: Imprensa Universitária, 2011.252 p.

14. Vassalo M, Fialho ET, Oliveira AIG. et. al. Probióticos para leitões dos 10 aos $30 \mathrm{~kg}$ de peso vivo. Revista Brasileira de Zootecnia. 1997; 26(1):131-138.

15. Canibe N, Højberg O, Badsberg JH, Jensen BB. Effect of feeding fermented liquid feed and fermented grain to piglets on gastrointestinal ecology and growth performance. Journal of Animal Science. 2007; 85: 2959-2971.

16. Luna, LG. Manual of histology staining methods of the Armed Forces Institute Pathology. 3. ed. New York: McGraw hill, 1968. 258p. English.

17. Nofrarías M, Manzanilla E G, Pujols J, Gibert X, Majó N, Segalés J, Gasa J. Effects of spray-dried porcine plasma and plant extracts on intestinal morphology and on leukocyte cell subsets of weaned pigs. Journal of 
Animal Science. 2006; 84:2735-2742.

18. SAS. Institute Statistical Analysis System: use guide [CD-ROM]. Version 8. Cary (NY): SAS Institute Inc., 2002.

19. Kijora C, Kupsch RD. Evaluation of technical glycerols from "biodiesel" production as a feed component in fattening pigs. European Journal of Lipid Science and Technology. 1996; 98: 240-245.

20. Kijora C, Bergner H, Kupsch RD, Hageman L. Glycerol as feed component in diets of fattening pigs. Archives of Animal Nutrition. 1995; 47:345-360.

21. Kijora C, Kupsch, RD.; Bergner H, Wenk C, Prabucki A L. Comparative investigation on the utilization of glycerol free fatty acids in combination with glycerol and vegetable oil in fattening of pigs. Journal Animal Physiology Animal Nutrition.1997; 77:127-138.

22. Carvalho P L O, Moreira I, Martins EN, Piano LM, Toledo JB, Costa Filho CL. Crude glycerine in diets for piglets. Revista Brasileira de Zootecnia. 2012; 41 (7): 1654-1661.

23. Gallego AG, Moreira I, Pozza PC, Carvalho PL de O, Sierra LMP, Costa Filho C de L. Neutral semipurified glycerin in starting pigs feeding. Semina: Ciências Agrárias. 2014; Londrina, 35 (5): 2831-2842.

24. Pluske JR, Hampson DJ, Williams IH. Factors influencing the structure and function of the small intestine in the weaned pig: a review. Livestock Production Sciences. 1997; 51:215-236.

25. Gomes JDF, Putrino SM, Martelli MR, Ishi M de P, Sobral PJ A, Fukushima RS. Morfologia de órgãos digestivos e não digestivos de suínos de linhagens modernas durante as fases de crescimento, terminação e pósterminação. Acta Scientiarum Animal Science. 2007; 29(3): 261-266.

26. Lin ECC. Glycerol utilization and its regulation in mammals. Annual Review of Biochemistry. 1977; 46:765-795.

27. Papadomichelakis G, Zoidis E, Mountzouris KC, Lippas T, Fegeros K. Glycerine kinase gene expression, nutrient digestibility and gut microbiota composition in post-weaned pigs fed diets with increasing crude glycerine levels. Animal Feed Science Technology. 2012; 177: 247-252.

28. Miller, B.G.; James, P. S.; Smith, M. W.; Bourne, F. J. Effect of weaning on the capacity of pigs intestinal villi to digest and absorb nutrients. Journal of Agriculture Science. 1986; 107 (3): 579-589.

29. Cera KR, Mahan DC, Cross RF, Reinhart GA, Whitmoyer RE. Effect of age weaning and postweaning diet on small intestinal growth and jejunal morphology in young swine. Journal Animal Science. 1988; 66: 574-584.

30. Manzanilla EG, Pérez JF, Martín M, Kamel C, Baucells F, Gasa J. Effect of plant extracts and formic acid on the intestinal equilibrium of early-weaned pig. Journal Animal Science. 2004; 82: 3210-3218. 